\title{
Conjectures on the Future of Ignorance
}

Mark N. Wexler

Simon Fraser University

Ignorance is not just a blank space on a person's mental map. It has contours and, for all I know, rules of operation as well. (Pynchon, 1984)

Ignorance is no small matter. While much time, money, and human energy is spent on the elimination of human ignorance, it is not quite clear how much of each expenditure is met with success or, for that matter, whether ignorance over time is or is not diminishing (Duncan \& Weston-Smith, 1977; O'Driscoll \& Rizzo, 1985). In a culture increasingly preoccupied with the efficient expenditure of time, money, and human energy, the problem of ignorance remains a sticky issue (Inglis, 1985; Loasby, 1976; Martin, 1981; Schneider, 1962; Smithson, 1985). It adheres easily to ideological assertions of progress and human betterment. Disputatious politicians assure us that the platforms of their opponents are laced with ignorance. Physicians attribute the wildfire spread of Acquired Immune Deficiency Syndrome to individual ignorance of preventive techniques. Educators catch the eye of pragmatic industrialists, perhaps in hopes of loosening their purses, by pointing out that an ignorant labor force impedes economic growth. The Japanese are, it is said, overtaking us economically because our school system fails satisfactorily to combat the spread of sloth and ignorance. The image of ignorance as vice permits theologians to bandy it about as if in a truly God-centered cosmology, the ignorant, defined as those unable to come to God, would disappear. Economists, too, in a rather secular cosmology redolent of invisible hands and the like, insist that in a perfectly competitive market we would not only eliminate ignorance but also achieve a perfectly poised, balanced, and flexible means of meeting our human needs.

The list of those who see, in ignorance and the ignorant, enemies of the good is legion. Theirs, to be sure, is no lazy rattling of intellectual sabers. Ignorance threatens. In it we possess no accurate cognitive map. Worse still, we take our existing cognitive map to be accurate (Weinstein \& Weinstein, 1978). In this context, to know one is ignorant, as all good Socratic thinkers know, is not to be ignorant at all but to be on 
the road to wisdom (Ballard, 1965; Drengson, 1981; Haden, 1984). Ignorance retains its problematic surface for several reasons. First, it irks those who believe it to be the source of human problems; second, like Freud's unconscious or Sartre's bad faith, to be in it is not to realize that one is at all; third, it generates the possibility of two frightening elements-uncertainty and, more strongly, the unknown. Taken to its logical conclusion, omniscience, the total realization of knowledge is deemed a utopian state; nescience, the total realization of ignorance, is fraught in the common imagination with subservience to dark forces, whether of Satan, madness, or illness (Houlgate, 1966; Martin, 1985; O'Gorman, 1986).

My work in this article is intended to portray the operations and contours of ignorance in such a manner that it becomes possible to drop the presumption that ignorance is diminishing as Homo sapiens moves, albeit tentatively, into the future. Our task in this article is to take ignorance seriously. By seriously, I mean that we will seek to understand ignorance as more than a vacant spot on a soon-to-be-filled map of human knowledge. Ignorance, I contend, can be thought of as having operations and contours of its own. It is a territory with rivers that sustain, mountains that divide, and is, of course, peopled by men and women who make much of what we call the future. Indeed, the role of human ignorance in the future cannot be dismissed as mere esoteric cartography. We live in times, I believe, in which to be ignorant of one's ignorance is to step perilously close to forfeiting an accurate map of our age.

To move from the metaphor of territories and maps to a less geographical frame, let us distinguish between two assertions of ignorance. The first, the one we shall label the weak assertion of ignorance, treats ignorance as if it were the absence of knowledge. It proceeds by excluding the wide middle between the knowledgeable and the ignorant. Moreover, it assumes that knowledge is commonly known and grows when ignorance is reduced. In the weak assertion of ignorance, we find buried an everyday epistemology which celebrates the inevitability of human progress. In this celebration, ignorance is portrayed as a force of darkness, the epicenter of the problematic, and in so doing a morality play is written into the heart of history.

The strong assertion of ignorance, on the other hand, treats ignorance as if knowledge of ignorance was no oxymoron. Within the weak assertion, one can logically only know the known; knowing ignorance is deemed itself a remarkable form of ignorance. This arises because in the weak assertion, ignorance is a blank or vacant spot on the map, a black box awaiting the 
advent of light to lend meaning to the meaningless; in the strong assertion of knowledge, ignorance is a vital part of the map, a necessary form of knowledge possessing its own ability to illuminate. In the strong assertion, ignorance is a contending form of knowledge. It receives its designation as ignorance not due to the existence of error, but due to suspension of certainty. Ignorance is knowledge with a center quite distinct from certainty and it leads over and over again into new possibilities. Fear of ignorance, within the strong assertion, is fear of the truly experimental nature of conjecture.

While my purpose is to provide an understanding of the future of ignorance, I must, on the whole, make it clear that the future which issues from the weak assertion of ignorance, the one which seeks to banish ignorance as a transitory vacant spot on the map, leads us to a very different future than does the strong assertion. These two futures are not caused by these assertions, but emanate from them insofar as human beings determine their futures by solving what they believe to be problematic.

Let us follow the future of ignorance stemming from the weak, then the strong, assertion of ignorance. The former leads us to the optimism of the rational progressivist. Here ignorance remains a phenomenon which must and will be diminished by the spread or diffusion of knowledge. The dark ages are all elsewhere. They are the past. They are a third world phenomenon. They exist in the minds of the mad, the biologically deficient and recalcitrant marginals who refuse to acknowledge the clarity of the known. The strong assertion, on the other hand, considers the dialectical relationship between the futures of ignorance and knowledge as an experiment, the outcome of which is not determined by the good intentions of those who sincerely believe themselves to be representatives of the forces of knowledge. Unlike the future generated by the weak assertion of ignorance, that of the strong fails to curb human anxieties. The dark ages, it can be argued, may exist now or indeed in our futures.

A man may live long and die at last in ignorance of many truths which his mind was capable of knowing, and with certainty.

(Locke, 1924, p. 62)

\section{Weak Assertion: Future of Ignorance}

To the British empiricists like John Locke, much of the tragedy of human mortality arises out of the incompletion of one's quest for knowledge. Death cuts short the capability of the mind to know with certainty that which seems within grasp. This tragedy is, Locke and other rational progressivists would have it, 
perpetuated on the level of the experiencing individual, not on the collectivity. On this level, whether the aggregate in question be the scientific community, the societal collective, or the world at large, Homo sapiens can over time create bodies of clear knowledge. In so doing, our species seeks to diminish pools of human ignorance. Ignorance is considered to be the source of uncertainty, indeed the haunt of human anxiety. It is thus not all accidental for a Newton to acknowledge his genius due to nothing but standing on the shoulders of previous generations of individuals who, like him, sought clarity.

The progressive rationalist is no lone figure. He or she is a firm believer in the doctrine which asserts that, due to the expansion and application of knowledge, mankind is far better off today than he or she has ever been. Within this perspective, the doctrine of social progress (Bury, 1955; Nisbet, 1980; Wagar, 1972) encapsulates the buoyant confidence of the empiricist. We are marching slowly but inexorably onward and upward. The credo is amelioration. Certainty or knowledge is the engine of this march; the impediment is ignorance. The confidence in this perspective is grounded in the firm conviction that Homo sapiens learns to correct error. The tool in this process varies with the audience to whom the perspective is argued. To some it is the hypothesis, to others the computer, while to still others it is the marketplace. No matter which is chosen as the tool, the result is similar-Homo sapiens is creating a world in which progress is equated with the increase in human knowledge and the decrease in ignorance.

The weak assertion of ignorance attains its designation as weak not because within this perspective ignorance is dismissed, but rather because it is vilified, perhaps even scapegoated, without being analyzed. In the weak assertion of ignorance, ignorance is weak because, like all straw men in arguments, it is set up merely to be knocked aside, replaced, if you will, by the growth and expansion of knowledge. Thus, while playing the role of villain, ignorance is imbued with neither the power nor majesty to go unchecked by the growth of knowledge.

The heroic nature of knowledge in the weak assertion exists for very good reasons. First it is true. This does not necessarily mean that knowledge is true for all situations or for all times, but within the canons of existing conventions it is deemed true. Second, it is clear or precise. Knowledge is not rooted in ambiguity, uncertainty, or subjective idiosyncrasies. It is a potentially useful, viable collection of potentially verifiable information. Third, it is shared. Knowledge must not only be verifiable, but the verification must be confirmed by others. 
Without this, individuals can fall prey to self-deception. Fourth, it is relevant. Knowledge is frequently equated with power for the very good reason that, like power, knowledge can get things done. Fifth, knowledge is growing and this at the expense of ignorance. Whether due to its relevance, its clarity, its communal base or truthlike formulation, knowledge, like a snowball rolling, is increasing over time.

Ignorance, on the other hand, while appearing to frighten as a good demon should, is actually treated like a rather static, indeed passive, black box. For rhetorical purposes, it is rolled out to serve as a foil for those whose image of the good world is being threatened. In this regard, ignorance can be thought of as the inability, usually of others, to know the correct, conventional, or clear way to go about things like acting, thinking, and the like. Thus the ignorant are those who are seen not only to act and think differently than the knowledgeable, but to do so despite opportunities to know better. The stigma which attaches to the immigrant, the nonconformist, and the illiterate is due to the resistance of each of these to the growth and expansion of knowledge. Therefore, as well, each is seen as a force which impedes progress.

The ignorant, like those who behold a false religion, must be taught the error of their ways. The act of teaching, after all, is for the benefit of those who otherwise would not reap the clarity, relevance, utility, and communal comfort of being knowledgeable. Knowledge in this perspective purifies. Ignorance, on the other hand, is an instance of the impure. It acts as an impediment on the collective effort to understand fully, to transcend our limited cognitive individual perceptions, and to create a fully comprehensible portrayal, chock full of certainty, of the big picture.

From the weak assertion of ignorance, we are led to a future of intolerance. Difference which irks is dismissed as ignorance. Rather than knowledge and the knowledgeable viewing ignorance and the ignorant (as reflected in all human beings) as indispensable partners in an ongoing dialectical process, adherents of the weak assertion would have us purge ignorance. Perhaps in an age of insecurity, difference is a reminder of the lingering incompletion of the quest for certainty. Perhaps in an age of anxiety, we really believe that if all were like us, knowledgeable, we would have far less to fear. No matter the conjecture, the future which emanates from the weak assertion of ignorance is one which is unforgiving in taking the high road in disputes and leaving only the very low for those who beg to differ. In fearing the dark ages, the logic of the weak assertion 
seeks to banish what it takes to be its manifestations. In so doing, much which points to alternate conceptions of the territory on which we walk with so much certainty may be lost. While we may be achieving a greater and greater consensus regarding the clarity of our map of the world and its affairs, we may be achieving this at the expense of refusing full knowledge status to those whose difference now goes underanalyzed as ignorance.

Whoever will be cured of ignorance, let him confess. (Montaigne, 1892, p. 103)

\section{Strong Assertion: Future of Ignorance}

Ignorance in the strong assertion is not a disease to be cured. It has to be defined in its own right, not glossed as the absence of good health (Cohen \& Taylor, 1978; Dennett, 1986; Hacking, 1986; Schedler, 1980). Indeed, in the strong assertion, to acknowledge one's ignorance is to make a strong claim not only to know with certainty what one knows beyond a shadow of a doubt, but also to begin to know what one doubts; stronger still, to know that one's knowing is part of a process which entails ignoring. The strong assertion of ignorance places ignorance in a different context than does the weak assertion. In the weak assertion of ignorance, the goal, as we have seen, is certainty. Knowledge is understood as a pure state which does not admit the contaminating blur of contradiction, ambiguity, and the idiosyncrasies of highly personalized preference. The formulation here is binary, not dialectic. A response is true or false. By eliminating all falsehoods or those suspicious enough to be unclear, we achieve certainty just as by eliminating all disease we arrive at good health. In the strong assertion, the goal is harmony. Ignorance is conceptualized as difference which can illuminate, not just irk, as is clear in the weak assertion.

The keen-eyed reader may feel that harmony and certainty are not nearly so distinct as is suggested by my efforts to compare the strong and weak assertions of ignorance. They are related but also are very distinct. They are related first because each reduces personal and collective anxieties. Thus, in the weak assertion, Locke's sense of tragedy at the elusiveness of certainty due to man's mortality, a source no doubt of great anxiety, is resolved. At the collective level in such enterprises as science, corporate governance, and the like, phenomena which extend the ambitions of human control to eliminate ignorance, Homo sapiens moves, as the doctrine of progress suggests, inexorably onward and upward. In this resolution, the anxieties produced by uncertainty are thus assured. The quest for certainty in the 
elimination of ignorance thus puts into perspective the personal limitations, including mortality, which each of us experiences and applauds the grand and broader field where Homo sapiens is mastering that which irks him or her.

In the strong assertion, harmony too is sought after to reduce personal and collective anxieties. The logic here, unlike that within the quest for certainty of the weak assertion, acknowledges the centrality of ignorance in the achievement of lessened anxieties. While the future emanating from the weak assertion of ignorance is full of intolerance and within it the search for mastery, dominion, and the elimination of troublesome differences, that within and emanating from the strong assertion seeks to accommodate. The quest for harmony, like that for certainty, is similar in its aim to reduce personal and collective anxieties. They are distinct in that the weak assertion seeks to eliminate ignorance and thus claim to understand it, while the strong assertion seeks to accommodate it.

What is, we may ask, harmonious about accommodating ignorance? This is a pivotal question. In responding to it we note how the strong assertion begins to map ignorance. In the strong assertion, as Montaigne (1892) makes clear, one ought not become too excited when eliminating one's ignorance, for it, like knowledge, is functional. In the weak assertion, ignorance functions solely as a means of defining knowledge. In the strong assertion, ignorance is not only necessary, it is also useful and may be sought after in its many guises by perfectly sane, intelligent, creative and, some would even argue, wise men and women.

At the individual level of the human being as a social actor, ignorance is a necessity. First, in order to behave at all, we must ignore all sorts of stimuli. To admit all the "booming, buzzing confusion" of the city streets as, let us say, a defensive driver, is to invite disaster. Focus or framing of attention requires exclusion. That which we ignore of necessity becomes in the strong assertion that of which we are ignorant. Note that in the strong assertion ignorance is not tied to relevance or indeed to intelligence. Ignorance is not, within the strong assertion, a sign of dumbness. In fact, as will become more apparent in the discussion of the strong assertion, at the collective level much of it comes about by design as in our efforts within complex bureaucracies to create focused specialization. Indeed, part of the complexity of modernity, its fragmentary nature, resides in our trust within the division of labor to remain ignorant regarding a great deal of that which we require. The act of teaching and writing papers such as this permits me to remain entirely ig- 
norant of the processes which propel the motor beneath my automobile hood.

Ignorance, still, at the individual level is useful. It is so useful that many of us have learned at strategic times to incorporate it into our behavioral repertoire in the hope that others will either lend us assistance or, as is equally likely, not hold us responsible for that which we may have been a part of. That which we feign is useful. Just as some of us may at times pretend to know that which we do not and see in it utility, so too, those of us who feign ignorance at equally opportune times need not be convinced of its utility.

The utility of ignorance is not exhausted in pretense. In the strong assertion, ignorance, once perceived by the individual as a natural, normal state of the human condition, permits him or her, as Socrates in his notion of Socratic ignorance makes clear, to begin the task of knowing himself or herself. In the weak assertion, the propensity is to externalize ignorance in the idea of irksome difference-the source of anxiety. In the strong assertion, ignorance is both internalized and externalized. Neither the individual nor the collective is omniscient. Each is striving to understand and accommodate the ongoing experiment in which it presently finds itself. Just as knowledge emerges, so too in the strong assertion does ignorance.

We discover ourselves in error not merely, as is the case in the weak assertion, to eliminate it, but in the strong assertion to accept it, even at times to come to appreciate it as a characteristic worth maintaining. The search for self-knowledge as a variant of knowledge entails the quest for harmony. The self is not merely a phenomenon to be controlled and moved toward the elimination of ignorance; it is an emergent search for selfappreciation, self-acceptance, and indeed the calm which accompanies the quest for harmony. The removal of anxiety at the personal level is in the strong assertion accomplished by living with and appreciating the tension in Jungian terms between the shadow which dwells in ignorance and the well-lit self which basks in knowledge.

At the collective level, ignorance is as necessary as knowledge. To have one, as we have seen in the notion of specialization, is to create the grounds for the other. The dialectic emerges. Ignorance and knowledge are interdependent. The society, community, or the corporation must deal not only with situations which are either true or false, but with ambiguous explorations which seek to satisfy different elements within the collective. Ignorance emerges in the strong assertion out of necessary 
difference. The difference is required if we are to have communities with differing values, perspectives, and attitudessocieties composed let us say of Christians, Jews, Muhammadans, and Hindus and corporations with line specialities and staff designations.

To map ignorance is to be aware that within the strong assertion this is no blank space, but a realm where others thrive with a sense of difference and purpose. Like the good anthropologist, one, if adhering to the strong assertion of ignorance, seeks to find there a tongue which utters sensibly and a heart which yearns for warmth and appreciation. The future emanating from the strong assertion of ignorance reduces human anxieties at the individual and collective levels by ascribing a sense of other to irksome difference. It does not, unlike the weak assertion, seek to eliminate it.

\section{Conclusion}

The world of the classroom is a microcosm of the changes about us. The weak assertion of knowledge is suited for the role of the educated man and woman as the legislator. The world, it is believed, can be controlled and mastered if and when the rules are made and followed correctly. The enemy is the anxiety which accompanies uncertainty. The method is structural. Difference, whenever possible, is to be nestled in containers which minimize the tension, friction, or just plain inefficiency which is believed to accompany unlegislated difference. Planning is possible if the rules, girded by the realism of probabilistic outcomes, are used to mobilize scarce resources, create consensus, and achieve the good life as the legislated and disciplined passage of one's hours on the planet.

Educating citizens for life in a legislated world makes ignorance the enemy. Ignorance is an antidote to legislatability. It is not at all accidental that denying the vote to the apparently illiterate, the colored, the female, or the native has been and, of course, continues to be an issue not merely because these folk are different but rather they are ignorant of the real ways of a legislatable world. This ignorance must be eliminated. The ignorant must be made aware of the actual agenda of our planetary existence, and this agenda is the one grounded in knowledge. This role of the legislator as pedagogical midwife to a materialist conception of order-a bureaucracy of the human condition-while easy to vilify when caricatured, is itself no simple straw man. The weak assertion of ignorance celebrates the possibility of a world in which Homo sapiens becomes omniscient and omnipresent. Evil, insofar as it is experienced, is 
banished. A wonderful calm is possible when ignorance and the ignorant are expunged, reformulated, and shown the error of their ways. The idea of a legislated perfect world is possible when all that is opaque is made clear; when the shadow world is put to the test of electric lighting, and wildness is given a place and time, so that others can, if they elect, avoid it.

The strong assertion of ignorance speaks not to the role of the educator and educated as the legislator and legislated, but to the problem of interpreter and the issue of interpretation. Interpretation addresses the possibility that error, when eliminated, and ignorance, when removed, is not the end of education. Interpretation entails the acceptance that difference is not merely to be controlled and its energy harnessed, but is also indispensable to the experience of learning and the testing of and dancing of varying attitudes all possible within the same self, the same corporation, the same state, the same world. While legislation clarifies the conventional, interpretation permits the questioning of possibles, indeed the postulating of impossibles. The line between real and unreal is essential in teaching and experiencing legislatively; the same line in teaching and experiencing interpretively is open to contention.

The act of interpretation sees ignorance not merely as the stumblebum antics of losers, mendicants, and the untrustworthy, but recovers the state of wonderment in the ignorance which accompanies conjecture. Ignorance in the interpretive form of pedagogy is no outlaw by definition, but rather a necessary adjunct to discovery, to innovation, to reframing and, indeed, carries minds into the much coveted but ill-articulated realms of creativity.

No simple tale of how to teach when and to whom is possible. The currents of our age, the Zeitgeist, recommend, I believe, serious consideration of ignorance, including one's own, as a necessary precondition of communicating more than the legislator's world view within the microcosm of the classroom. No rules append themselves simply to those seeking to find out what it is they do not know. Ignorance may not be as easily reduced as we think once we see it as more than a blank space on a mental map, once we see it as part of the struggle to articulate with a high possibility of saying something foolish, dangerous, or, most tragically, wrong.

\section{References}

Ballard, E.G. (1965). Socratic ignorance. The Hague: Nijhoff.

Bury, J. (1955). The idea of progress. New York: Dover Publications. 
Cohen, S., \& Taylor, L. (1978). Escape attempts: The theory and practice of resistance to everyday life. Harmondsworth, UK: Penguin.

Dennett, D. (1986). Information technology and the virtues of ignorance. Daedalus, 115, 135-148.

Drengson, A.R. (1981). The virtue of Socratic ignorance. American Philosophical Quarterly, 18, 237-242.

Duncan, R.F., \& Weston-Smith, M. (Eds.). (1977). Encyclopedia of ignorance. Oxford: Pergamon Press.

Hacking, I. (1986). Culpable ignorance and interference effects. In D. Maclean (Ed.), Values at risk (pp. 136-154). Ottawa: Rowan and Allenfield.

Haden, J. (1984). Socratic ignorance. In E. Kelly (Ed.), New essays on Socrates (pp. 17-28). Lanham: University Press of America.

Houlgate, L. (1966). Acts owing to ignorance. Analysis, 27, 17-22.

Inglis, F. (1985). The management of ignorance. London: Blackwell.

Loasby, B.J. (1976). Choice, complexity and ignorance. London: Cambridge University Press.

Locke, J. (1924). Essay concerning human understanding. Oxford: Clarendon Press.

Martin, A. (1981). The genesis of ignorance: Nescience and omniscience in the Garden of Eden. Philosophy and Literature, 5, 3-20.

Martin, A. (1985). Knowledge of ignorance. New York: Cambridge University Press.

Montaigne, M. (1892). Essays, done into English. London: Nutt.

Nisbet, R.A. (1980). History of the idea of progress. New York: Basic Books.

O'Driscoll, G.P., \& Rizzo, M. (1985). The economics of time and ignorance. New York: Blackwell.

O'Gorman, H.J. (1986). The discovery of pluralistic ignorance: An ironic lesson. Journal of the History of the Behavioral Sciences, $22,333-347$.

Pynchon, T. (1984). Slow learner: Early stories. Boston: Little, Brown.

Schedler, G. (1980). The argument from ignorance. International Logic Review, 11, 66-71.

Schneider, L. (1962). The role of the category ignorance in sociological theory: An exploratory statement. American Sociological Review, 26, 492-508.

Smithson, M. (1985). Toward a social theory of ignorance. Journal for the Theory of Social Behavior, 15, 150-172.

Wagar, W. (1972). Good tidings: The belief in progress from Darwin to Marcuse. Bloomington, IN: Indiana University Press.

Weinstein, D., \& Weinstein, M. (1978). The sociology of nonknowledge: A paradigm. In R.A. Jones (Ed.), Research in the sociology of knowledge. Greenwich, CN: JAI Press. 